Journal of Computer Science 6 (4): 446-449, 2010

ISSN 1549-3636

(C) 2010 Science Publications

\title{
Simulation of Phosphorus Movement in Unconfined Aquifer by Means of Visual MODFLOW
}

\author{
${ }^{1}$ Seyed Reza Saghravani, ${ }^{1}$ Sa' ari Mustapha, ${ }^{2}$ Shaharin Ibrahim, \\ ${ }^{3}$ Mohd. Azwan Mohd. Zawawi and ${ }^{4}$ Elias Randjbaran \\ ${ }^{1}$ Department of Chemical and Environmental Engineering, Faculty of Engineering, \\ ${ }^{2}$ Department of Environmental Science, Faculty of Environmental Studies, \\ ${ }^{3}$ Department of Biological and Agricultural Engineering, Faculty of Engineering, \\ ${ }^{4}$ Department of Mechanical and Manufacturing Engineering, Faculty of Engineering, \\ University Putra Malaysia, 43400 UPM-Serdang, Selangor, Malaysia
}

\begin{abstract}
Problem statement: In three recent decays, computer software's are used for assessing and predicting of what happened and what will happen for surface and subsurface water. These supplementary tools are calculating and presenting potential recharge of contamination to estimate and assess important issue in hydrogeology such as amount of contamination in drinking water. There is a source of contamination in study area that was approved by some experiments in laboratory. In present study, movement of contamination horizontally and vertically simulated. Approach: Visual MODFLOW used to determine movement of groundwater and fate of contamination (phosphorus) by two different types of computers. Results: The results showed that both computers were able to run the software without critical problem. Also it was found that vertical migration is mainly responsible to migration of contamination. Conclusion: In conclusion, the software performance can be skilful and accomplished. It is able to solve a wide range of research problems with low rate of the errors.
\end{abstract}

Key words: Visual MODFLOW, phosphorus, groundwater, vertical migration, Malaysia

\section{INTRODUCTION}

Computer modelling and simulation are applying to predict water movement and contamination migration in surface water and groundwater regime, and interaction between these two sources of water. In comparison with surface water, simulation of groundwater is more important because monitoring of water under surface and tracking of movement and hidden source of water and contaminants is more complicated. Groundwater investigation by modelling has been known to scientists for long time since assessment and monitoring of the underground reservoirs are too difficult exercises. These methods are reliable to determine the groundwater flow and transport of contamination by mathematical equations based on certain simplifying assumption (Kumar, 2007).

Groundwater simulation by computer is a specialized field that requires considerable training and experience. In the last few decades, hundreds of computer codes for simulating various aspects of soil groundwater systems have been developed. Some of these softwares are Groundwater Modelling System (GMS), Groundwater Vistas, Visual MODFLOW, MODFLOW SURFACT, POLLUTION and they are using all over the world by different environmentalists, hydrologists and hydrogeologists (Boulding and Ginn, 1995).

The great advantage of the computer is large amounts of data can be processed promptly, while experimental modification can be provided by minimal effort, in order that many possible situations for a given problem were studied in great details. However, most of software package, such as Groundwater Vistas, Visual Argus ONE, Groundwater Modelling System (GMS) and recently MODFLOW-CFP using MODFLOW for modeling.

MODFLOW (three-dimensional block-centred finite-difference groundwater flow model), a computer program, has been developed by McDonald and Harbaugh (1988) in the form of modular threeDimensional groundwater flow model for US Geological Survey. MODFLOW is able to simulate a wide range of flow in porous media with wide varieties of systems and standard including groundwater flow,

Corresponding Author: Seyed Reza Saghravani, Department of Chemical and Environmental Engineering,

Faculty of Engineering, University Putra Malaysia, 43400 UPM-Serdang, Selangor, Malaysia 
transport of contamination and mine dewatering (Harbaugh, 2005).

MT3DMS is a three dimensional multispecies contaminant transport model for simulating of solute transport processes (Zheng, 2009). It is based on the advection-dispersion formulation for modelling of saturated and unsaturated zone and also interaction between surface water and subsurface water.

MT3DMS contains different techniques including the third-order Total Variation Diminishing (TVD), fully implicit Finite-Difference Method (FDM), and particle tracking based Method Of Characteristics (MOC). There has been a wide development in MT3DMS since the first released in 1990 which was known as MT3D. It supports simulation of different species mass transport. Nevertheless, in first edition it used for simulating of single species.

Visual MODFLOW combines MT3DMS and MODFLOW to flow and transport modelling under different condition. MT3DMS was developed as supplementary software to the USGS's MODFLOW. Therefore, it is designed to support the features of MODFLOW. This decoupled approach allows having complete simulation of flow and transport with maximum efficiency.

In this article, migration of contamination in steady state and transient were simulated. The results were obtained by using Visual MODFLOW Version 4.2 for predicting migration of contamination in pond, swamp and groundwater and interaction between them in the study area for 50 years.

\section{MATERIALS AND METHODS}

How we simulate: The software runs in two different computers. First time a notebook computer equipped with an Intel Core 2 Duo T5500 (1.66 GHz) and 1 GB RAM. Second time using a desktop computer equipped with an Intel Pentium Processor G6950 (3M Cache, $2.80 \mathrm{GHz}$ ). The operating systems in both computers were Windows XP Professional. MT3DMS and MODFLOW were selected to run and calculate the groundwater movement and also phosphorus flow rate. It is to be noted that aquifer assumed heterogeneous and anisotropic.

Conceptual model: There are two Governing equations for modelling of groundwater and contamination has been used. These can be written as:

- The mathematical representation of three dimensional groundwater flow equation represents below (Harbaugh, 2005):

$$
\begin{aligned}
& \frac{\partial}{\partial x}\left(K_{x x} \frac{\partial h}{\partial x}\right)+\frac{\partial}{\partial y}\left(K_{y y} \frac{\partial h}{\partial y}\right) \\
& +\frac{\partial}{\partial z}\left(K_{z z} \frac{\partial h}{\partial z}\right)-W=S_{s} \frac{\partial h}{\partial t}
\end{aligned}
$$

Where:

$\mathrm{K}_{\mathrm{xx}}, \mathrm{K}_{\mathrm{yy}}, \mathrm{K}_{\mathrm{zz}}=$ Values of hydraulic conductivity along the $\mathrm{x}, \mathrm{y}$, and $\mathrm{z}$ directions, which are assumed to be parallel to the major axes of hydraulic conductivity

$\mathrm{h}=$ Piezometric head

$\mathrm{W}=$ Volumetric flux per unit volume that is represented for pumping, recharge, or other sources and sinks

$\mathrm{S}_{\mathrm{S}} \quad=$ Specific storage coefficient

$\mathrm{x}, \mathrm{y}, \mathrm{z}=$ Coordinate direction

$\mathrm{t}=$ Time

- The following equation represents transport of contaminations in groundwater flow systems (Zheng, 2006):

$$
\begin{aligned}
\frac{\partial\left(\omega C^{k}\right)}{\partial t}= & \frac{\partial}{\partial x_{i}}\left(\omega D_{i j} \frac{\partial C^{k}}{\partial x_{j}}\right)-\frac{\partial}{\partial x_{i}}\left(\omega v_{i} C^{k}\right) \\
& +q_{s} C_{s}^{k}+\sum R_{n}
\end{aligned}
$$

Where:

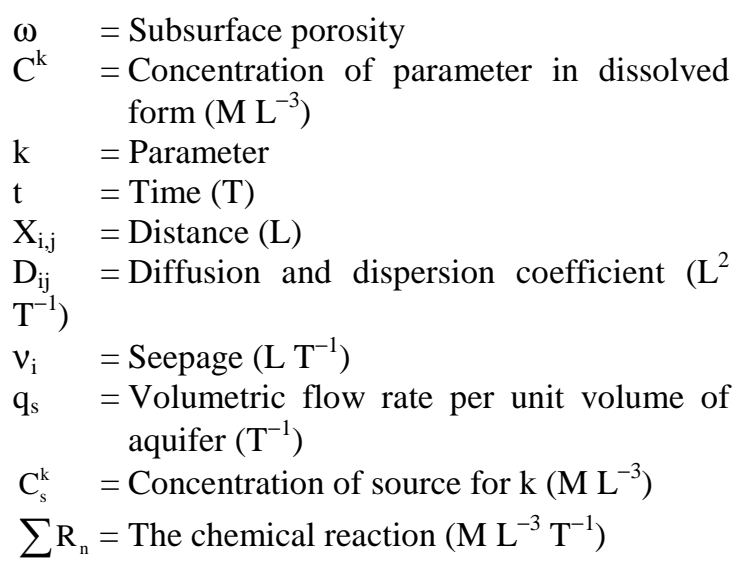

\section{RESULTS AND DISCUSSION}

Application to the test site: Groundwater system investigated is placed in vicinity of University Putra Malaysia in south of Kuala Lumpur. Aquifer includes two layers, clay loam and limestone as first and second layers respectively. The following parameters are used for the duration of simulation: Hydraulic conductivity 
both vertical and horizontal, total porosity, effective porosity, specific yield, specific storage, dispersivity, concentration of contamination (i.e., Phosphorus), groundwater level, evapotranspiration, groundwater recharge. We predicted the groundwater flow and contamination destiny in (1) Transient and (2) Steady State. The boundary conditions in these two prediction processes are different. In Steady State groundwater head and groundwater flow direction remains constant during the period of simulation. In other words, the water did not descend. On the contrary, in transient assumed that water in Pond is reduced two metres and direction of groundwater flow has been changed.

Figure 1 presents the model domain and gridlines which is designed for current research. The dots inside the study area are represented location of boreholes. These boreholes are used for gathering data from underground water.

Software performance: We ran a problem with two different types of assumption. (1) In steady state; we assumed that groundwater has stable movement in normal direction, (2) in transient; we assumed that water will be dropped two meters in pond. Consequently, groundwater movement direction will be changed. Calibration of simulation has shown that normalized Root Mean Square for concentration of contaminant was $28.6 \%$, and standard error of the estimate was $0.057 \mathrm{mg} \mathrm{L}^{-1}$.

In addition, software is able to solve different types of critical problem for groundwater flow and transport of contaminants.

What we found: Measurement of phosphorus in different parts of study area shown that its concentration in swamp is highest in comparison with pond and samples which gathered from observation wells.

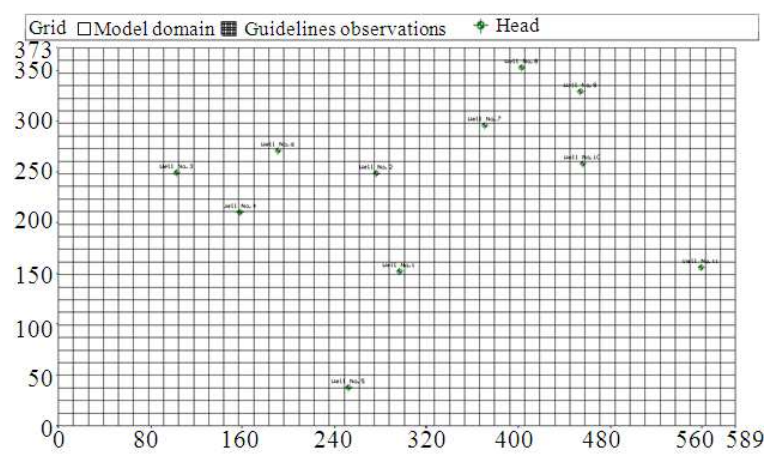

Fig. 1: Model domain and gridlines
Simulation was done for two layers. Differences in results are due to soil characteristics of the layers, rainfall, evapotranspiration and other parameters that affect the results. Contamination in layer No. 1 (i.e., clay loam) has very small movement due to small hydraulic conductivity of soil and natural mobilization of phosphorus. Phosphorus was transported toward pond via the first layer, although time was not enough to reach at pond. It means 50 years is not enough to receive a high concentration of pollution just through layer No.1, even if the combination of these two layers is capable of such transportation (Fig. 2).

However, a fast progression of the pollution plume is revealed which indicates that the contamination plume moves faster than the upper layer. Source of contamination was located in the first layer and it should be infiltrated through the first layer to reach to the second one. This means that vertical migration is responsible for the occurrence of phosphorus beneath the swamp.

In comparison with first layer, concentration of phosphorus after 50 years in second layer (limestone) is lower. In spite of this, contamination is received by the pond as a result of pollutant migration through limestone. Attributable to low hydraulic conductivity of first layer, the pollutant had reached the pond through movement of pollutant from polluting source i.e. the swamp through limestone. Therefore, vertical migration is responsible for the occurrence of phosphorus beneath the swamp elevation (Fig. 3).

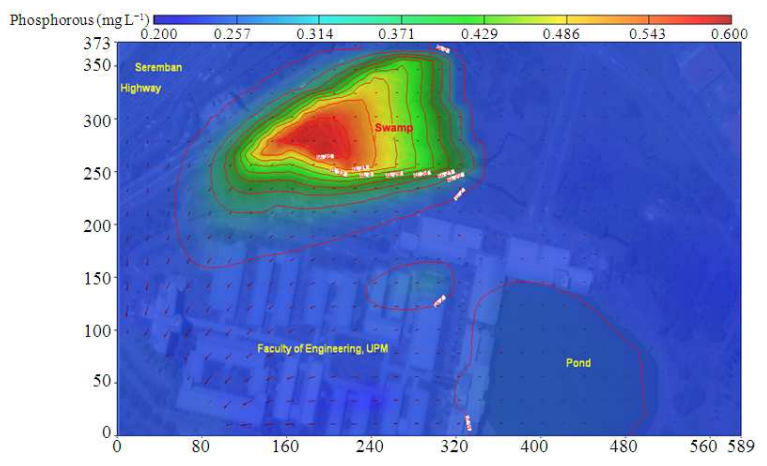

Fig. 2: Simulation of phosphorus in steady state (50 years)

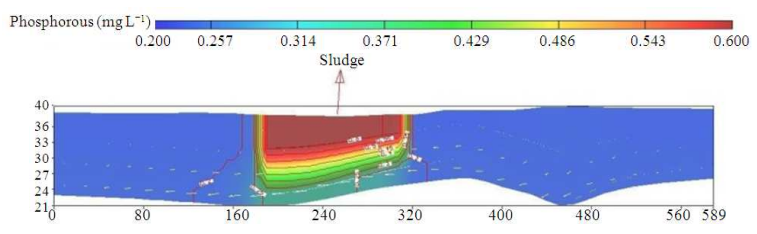

Fig. 3: Cross sectional view of computer model and simulation of groundwater movement 


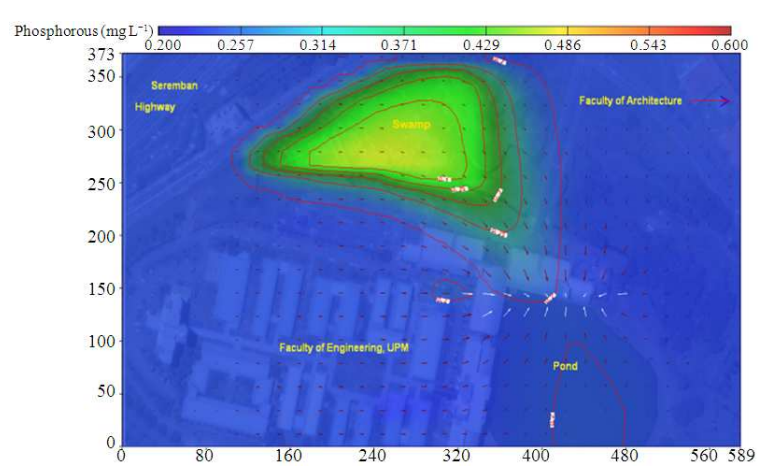

Fig. 4: Simulation of phosphorus in transient (50 years)

The type of soil in first layer permits phosphorus to slowly enter only into second layer (Fig. 4).

\section{CONCLUSION}

The visual MODFLOW can be named user friendly software because of simple method for inputting data and running the software. There is no critical problem in working with the software in both sets of computers. It is stable software that is using for different types of modelling in hydrogeology. However, we observed two or three times crashes in software during the running process in desktop computer which was connected to software through the network.

In conclusion, visual MODFLOW can currently address transport or contamination reaction and fate. With regard to type of boundary condition, the results are different to applied in present research. But main point and variety in movement of contamination is due to different hydraulic conductivity and other properties of soil.

\section{REFERENCES}

Boulding, J.R. and J.S. Ginn, 1995. Practical Handbook of Soil, Vadose Zone and Groundwater Contamination. Lewis Publishers, USA., ISBN: 13: 978-1566700511 1995, pp: 960.
Harbaugh, A.W., 2005. MODFLOW-2005, the US geological survey modular ground-water model. The ground-water flow process. US Geological Survey, Reston, Virginia. http://pubs.water.usgs.gov/tm6A16/

Kumar, C.P., 2007. Groundwater Flow Models. National Institute of Hydrology, pp: 26. http://www.angelfire.com/nh/cpkumar/publication/ flowmodels.pdf

McDonald, M.G. and A.W. Harbaugh, 1988. A Modular Three-Dimension Finite-Difference Groundwater Flow Model. US Geological Survey. Washington DC., p: 875. http://pubs.usgs.gov/twri/twri6a1/

Zheng, C., 2006. MT3DMS v5.2. A modular threedimensional multi-species transport model for simulation of advection, dispersion and chemical reactions of contaminants in groundwater systems: Supplemental User's Guide. Department of Geological Sciences, University of Alabama, pp: 24. http://hydro.geo.ua.edu/mt3d/mt3dms_v5_supplem ental.pdf

Zheng, C., 2009. Recent development and future directions for MT3DMS and related transport codes. Groundwater, 47: 620-625. DOI: 10.1111/j.1745-6584.2009.00602.x 